\title{
Squamous cell carcinoma of the kidney in an End Stage Renal disease patient in a tertiary health care center; a case report and review of literature, Assiut university hospital experience 2021,
}

abdelrahman mohamed abdelkader ( $\sim$ abdelrahmanmohamed.aa@gmail.com )

Assiut University https://orcid.org/0000-0003-1217-7279

mohamed Zarzour

Assiut University Faculty of Medicine

Research Article

Keywords: ESRD, rare, recurrent, surgery, salvage

Posted Date: November 2nd, 2021

DOI: https://doi.org/10.21203/rs.3.rs-1024870/v1

License: (a) (i) This work is licensed under a Creative Commons Attribution 4.0 International License.

Read Full License 


\section{Abstract}

The literature mentioned few case that are squamous cell carcinoma of the renal pelvis since 1955. Renal cell carcinoma with all its variants represent more than ninety percent, the remaining ten percent is divided on urothelial tumors, sarcomas and metastasis from other organs. Squamous cell carcinoma of the urothelium is not common, but in Egypt it was very frequently seen in the bladder, multiple cause are proposed such as the chronic irritation caused by Schistosomiasis infection. The general role of this type is that it is resistant to both chemo and radiotherapy with fair outcome to surgery if early intervention was done. This article will discuss a case that developed squamous cell carcinoma in the renal bed after nephrectomy, which was managed with excellent outcome in assiut university hospital

\section{Case Report}

A male patient 47 years old ESRD on regular dialysis for eleven years, no other comorbidity were found beside history of a lower urinary tract surgery either in the bladder or ureter 17 years ago and a left subcapsular nephrectomy 2019 at our department because he was complaining of persistent pyuria per urethera . After two years he presented with left loin pain and swelling that kept increasing in size and then eventually a skin sinus developed. MRI was done and showed a large lobulated mass at site of renal bed infiltrating the psoas muscle and lateral wall muscle measuring $14.5^{\star} 7.5 \mathrm{~cm}$ with restricted diffusion. After reviewing his old biopsy it showed squamous metaplasia of the pelvicalyceal system and chronic glomerulonephritis. Ct guided biopsy revealed areas of hyperplastic squamous epithelium, strips of chronic inflammatory cellular infiltrate \& the cells showed prominent nucleoli with occasional mitosis and extensive keratinization. His labs were within normal serum creatinine was five, hemoglobin was ten. Urgent salvage surgery was performed. A chevron incision was done, adhesiolysis and dissection of massive peritoneal and colonic adhesion until the retroperitoneal space is reached. A fungating mass is found infiltrating most of the posterior abdominal wall muscles and the rib, it was found to infiltrate part of omentum. Excision of the mass and most of the necrotic tissue, closure was done in layers despite the difficulty we faced due to the extensive loss in tissue architecture resulting from extensive infiltration of the tumor. The patient had a smooth postoperative recovery and drain was removed after five days, the wound showed some discharge which was trivial. He was discharged after 9 days. He was presented in the follow up after three month with satisfactory performance and a good wound healing. His biopsy showed moderately differentiated squamous cell carcinoma.

\section{Discussion}

The most common variant of renal cell carcinoma in ESRD patients is papillary renal cell carcinoma . $(1,2)$ Squamous cell carcinoma of the renal pelvis is a very rare variant, its incidence range from less than 1 percent to less than 5-10 percent of all the upper urothelial tract tumors. $(3,4)$ Squamous cell carcinoma in ESRD is mentioned in the literature very few, There is no definite cause to blame, but smoking, recurrent operation as PCNL, chronic irritation caused by stones or infection and squamous metaplasia are risk factors. ${ }^{(5-7)}$ The most common cause is stones leading to squamous metaplasia, which was found in 
the previous kidney specimen that was removed from the patient two years ago. Squamous metaplasia considered by some authors as precancerous lesion, occurs more in the lower tract unlike the upper tract, and requires strict follow up. ${ }^{(5,8)}$ The clinical presentation of the disease includes no characteristic symptoms and signs, making it very difficult to diagnose as in this case the diagnosis was difficult, all the signs were making the diagnosis directed toward infection or retro-peritoneal abscess also the CT guided biopsy was not conclusive, until exploration was done. ${ }^{(9)}$ Pain, hematuria, local swelling of the loin and a fistula formation or skin sinus as in our patient are symptoms that may occur in advanced disease $(5,7,10)$ . The treatment is radical surgery, due to the rarity of the cases the conclusive decision of applying radiotherapy or chemotherapy either in advanced or early cases, preoperatively or postoperatively, can't be taken. ${ }^{(10-12)}$ To achieve similar outcome as transitional cell carcinoma the diagnosis must be early, as the main problem with this variant is its delayed diagnosis either according to the clinical picture or radiological ${ }^{(13)}$.

\section{Conclusion And Recommendation}

Squamous cell carcinoma of renal pelvis is rare and highly aggressive. It has a high recurrence rate and low mean survival rate. Best treated by surgery. Our case is on regular dialysis that developed the recurrent tumor after nephrectomy for another cause. Stones, infection should be managed as early as possible with prevention of their recurrence. Nephrectomy in case of complicated renal disease should be radical. Regular follow up cystoscopy is required.

\section{Declarations}

- Ethics approval and consent to participate

Yes the patient was approving

- Consent for publication

Taken from the patient and family

- Competing interests :no

- Funding: no

- Authors' contributions both authors made equal efforts

- Acknowledgements : no

- Data available : yes

\section{References}

1. Tickoo SK, dePeralta-Venturina MN, Harik LR, Worcester HD, Salama ME, Young AN, et al. Spectrum of Epithelial Neoplasms in End-Stage Renal Disease: An Experience From 66 Tumor-Bearing Kidneys 
With Emphasis on Histologic Patterns Distinct From Those in Sporadic Adult Renal Neoplasia. American Journal of Surgical Pathology. 2006 Feb;30(2):141-53.

2. Nakanishi Y, Koga F, Fukushima H, Motoi T, Tobisu K. Renal Cell Carcinoma in End-Stage Renal Disease [Internet]. Updates in Hemodialysis. IntechOpen; 2015 [cited 2021 Oct 7]. Available from: https://www.intechopen.com/chapters/47748

3. Brits NF, Bulane S, Wadee R. Primary squamous cell carcinoma of the kidney: a case report and review of the literature. African Journal of Urology. 2020 Dec 3;26(1):79.

4. Bhaijee F. Squamous cell carcinoma of the renal pelvis. Annals of Diagnostic Pathology. 2012 Apr;16(2):124-7.

5. Chang T-H, Tseng J-S. Rare squamous cell carcinoma of the kidney with concurrent xanthogranulomatous pyelonephritis: A case report and review of the literature. Open Med (Wars). 2021 Jan 12;16(1):128-33.

6. Genega EM, Porter CR. Urothelial Neoplasms of the Kidney and Ureter. Pathology Patterns Reviews. 2002 Jun 1;117(suppl_1):S36-48.

7. Sun $X$, Li Y. Incidental squamous cell carcinoma of renal pelvis presenting as skin invasion: a case report. Journal of Medical Case Reports. 2020 Dec 15;14(1):244.

8. Ganeshappa A, Krambeck A, Grignon DJ, Lingeman JE. Endoscopic Management of Keratinizing Desquamative Squamous Metaplasia of the Upper Tract: A Case Report and Review of the Literature. Journal of Endourology. 2009 Aug;23(8):1277-9.

9. Paonessa J, Beck H, Cook S. Squamous cell carcinoma of the renal pelvis associated with kidney stones: a case report. Med Oncol. 2011 Dec 1;28(1):392-4.

10. Jiang P, Wang C, Chen S, Li J, Xiang J, Xie L. Primary renal squamous cell carcinoma mimicking the renal cyst: a case report and review of the recent literature. BMC Urology. 2015 Jul 23;15(1):69.

11. Ghosh P, Saha K. Primary Intraparenchymal Squamous Cell Carcinoma of the Kidney: A Rare and Unique Entity. Case Reports in Pathology. 2014 Jan 20;2014:e256813.

12. Martin JW, Carballido EM, Ahmed A, Farhan B, Dutta R, Smith C, et al. Squamous cell carcinoma of the urinary bladder: Systematic review of clinical characteristics and therapeutic approaches. Arab Journal of Urology. 2016 Sep;14(3):183-91.

13. Hosseinzadeh M, Mohammadzadeh S. Primary Pure Squamous Cell Carcinoma of Kidney Associated with Multiple Stag Horn Stones. Int Med Case Rep J. 2020;13:261-3.

14. Sahoo TK, Das SK, Mishra C, Dhal I, Nayak R, Ali I, et al. Squamous Cell Carcinoma of Kidney and Its Prognosis: A Case Report and Review of the Literature. Case Reports in Urology. 2015;2015:1-3.

\section{Figures}




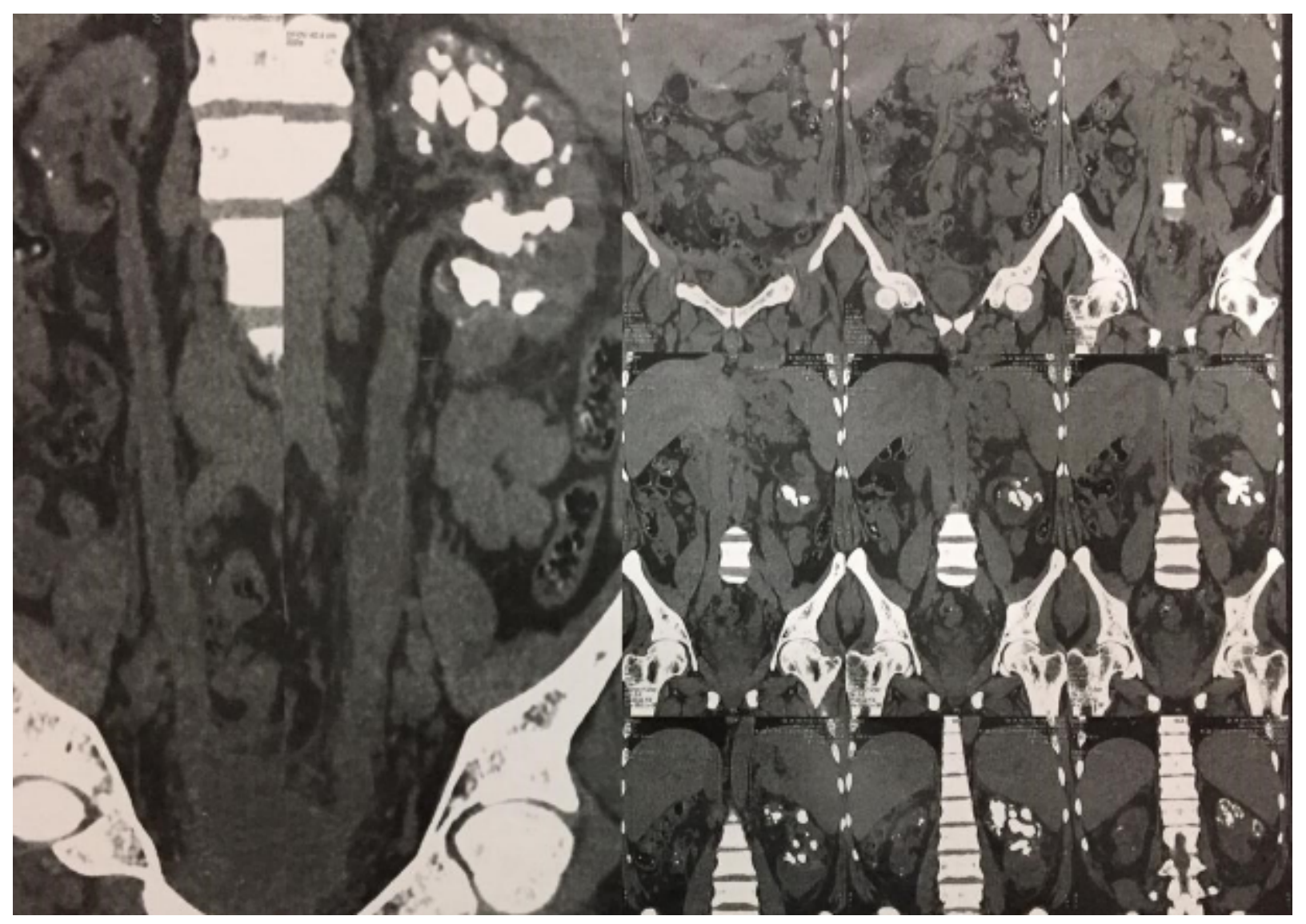

Figure 1

ct image before nehprectomy

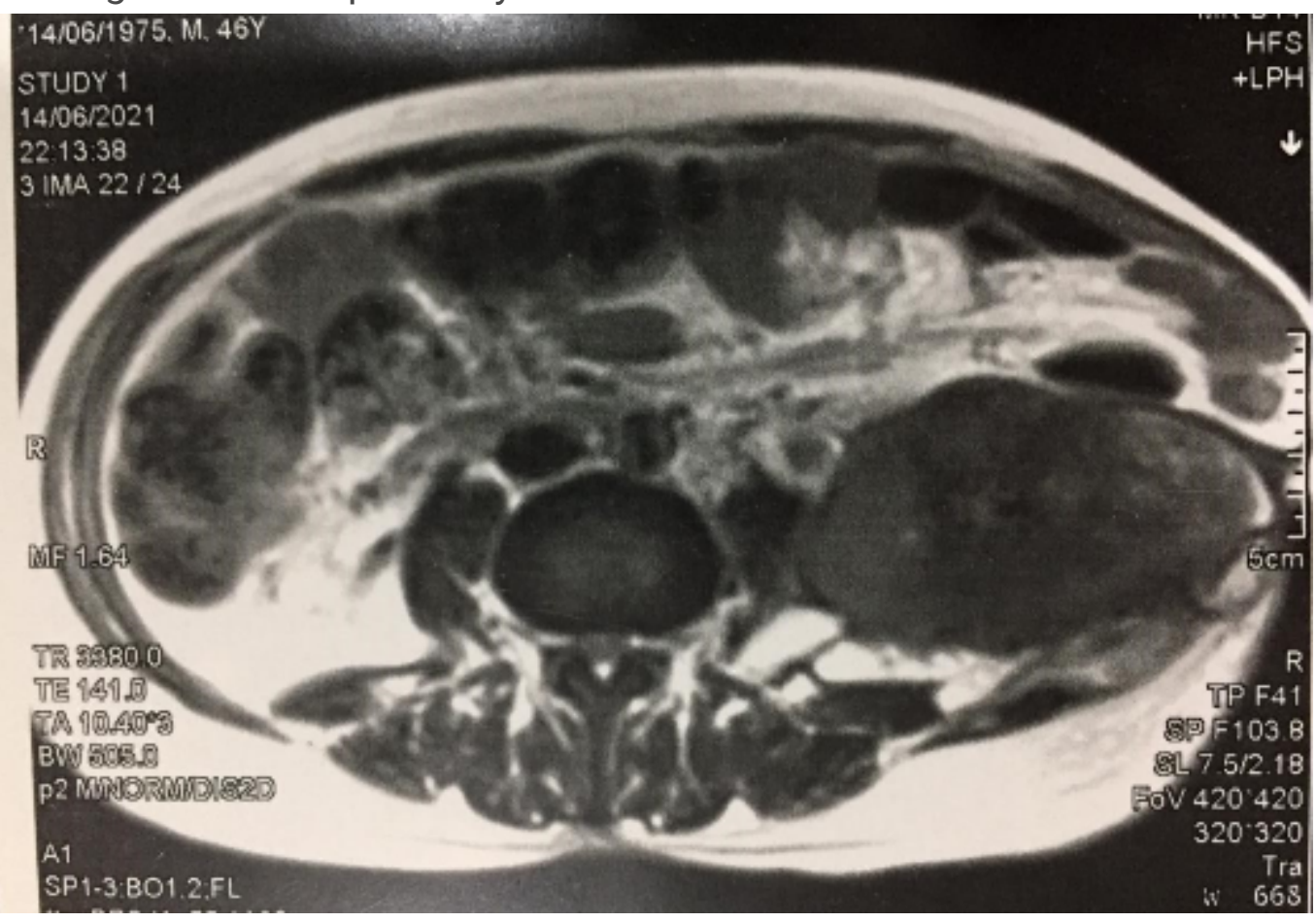

Figure 2 
mri showing the extent of the recurrent mass

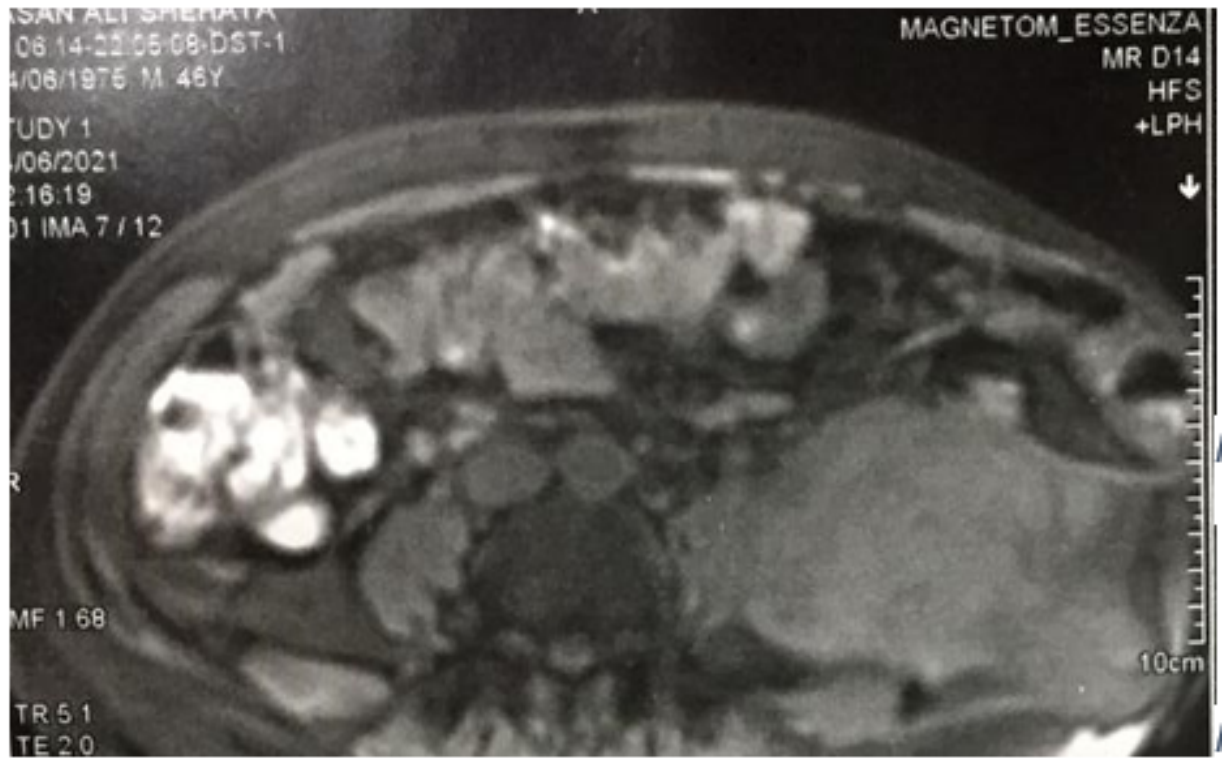

\section{Figure 3}

mri showing the mass infiltration up to skin

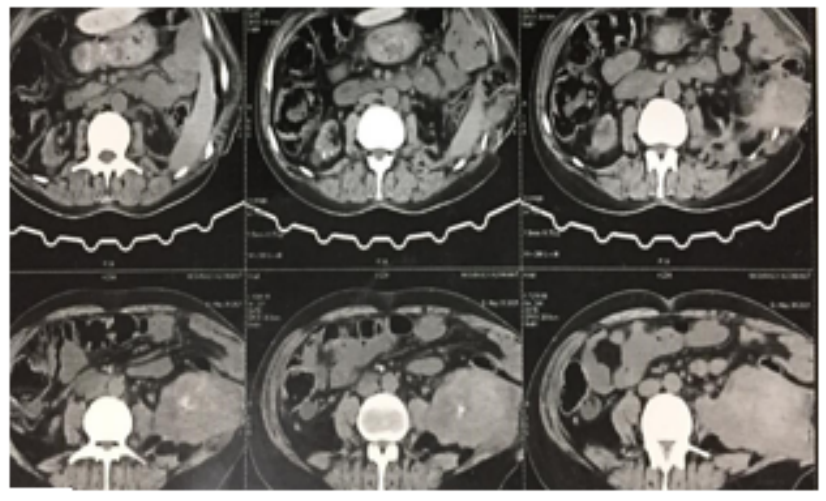

\section{Figure 4}

ct showing the mass infilteration

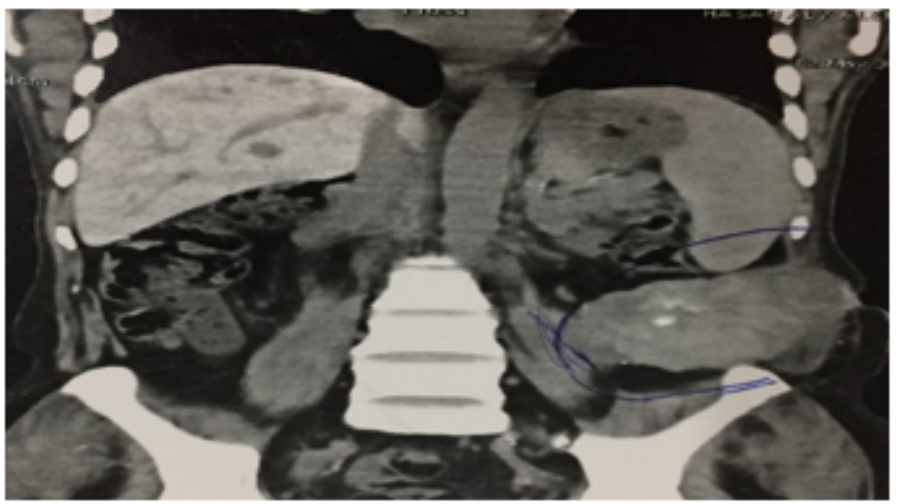

Figure 5 
ct showing the mass

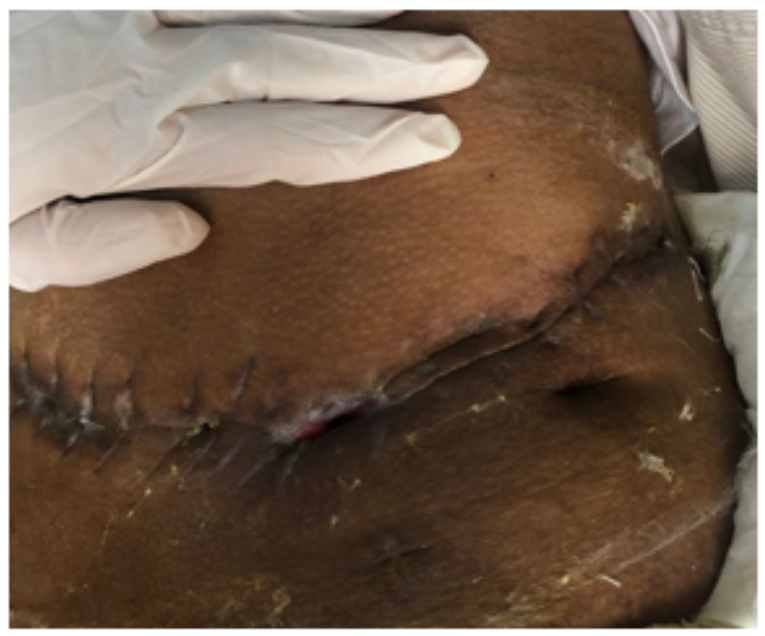

Figure 6

post operative 